Tropical Journal of Pharmaceutical Research September 2015; 14 (9): 1589-1595

ISSN: 1596-5996 (print); 1596-9827 (electronic)

(C) Pharmacotherapy Group, Faculty of Pharmacy, University of Benin, Benin City, 300001 Nigeria.

All rights reserved.

Available online at http://www.tjpr.org

Original Research Article

http://dx.doi.org/10.4314/tjpr.v14i9.7

\title{
Inhibitory Effect of Berberine on Zeste Homolog 2 (Ezh2) Enhancement in Human Esophageal Cell Lines
}

\author{
Si-Ze Chen ${ }^{1 \star}$, Xue-Mei Chen ${ }^{2}$, Yu-Qi Li ${ }^{1}$, Fan Zhang ${ }^{1}$, Shu Yang ${ }^{1}$, Kai Lan Mo ${ }^{1}$, \\ Xian-Yi Mo ${ }^{1}$ and Ying Ding ${ }^{1}$ \\ ${ }^{1}$ Department of Oncology, The First Affiliated Hosipital of Guangdong Pharmaceutical University, ${ }^{2}$ Department of Occupational \\ Medicine and Health, Southern Medical University, Guangzhou, China
}

*For correspondence: Email: chensize37@gmail.com

Received: 5 January 2015

Revised accepted: 24 July 2015

\begin{abstract}
Purpose: To investigate the inhibitory effect of berberine treatment on enhancement of zeste of homolog 2 (Ezh2) expressions in KYSE450 human esophageal cancer cells.

Methods: Transwell motility chambers were used to analyze cell migration and invasion. Bio-Rad protein assay was used for the determination of protein concentration. Chemiluminescence with ECL system was employed for the detection of protein bands as per the manufacturer's protocol. Staining was carried out with Alexa-Fluor 647 mouse anti-BrdU antibody. Flow cytometry was performed after adding DAPI. Annexin-V/DAPI staining and flow cytometry were used for the quantification of apoptotic cell death. Total RNA was isolated from KYSE450 cells using an RNA isolation kit.

Results: Berberine-induced inhibition of Ezh2 expression led to inhibition of cell proliferation by G1 phase cell cycle arrest and induced anti-invasive properties of KYSE450 cells in Boyden chamber assays. There was $92 \%$ reduction in invasive tendency of KYSE450 cells following treatment with berberine. Histone methylation inhibitor, 3-deazaneoplanocin A (DZNep), also led to a similar effect on cell proliferation of KYSE450 cells. Berberine treatment also resulted in strong transcriptional reduction of the AXL receptor kinase. The results of qRT-PCR and FACS analyses showed significant inhibition of AXL mRNA and protein expression in KYSE450 carcinoma cells after treatment with berberine.

Conclusion: Berberine may be an effective therapeutic agent in the treatment of esophageal carcinoma.
\end{abstract}

Keywords: Berberine, Histone methylation inhibitor, Anti-invasive, Cell proliferation, Human Esophageal cancer

Tropical Journal of Pharmaceutical Research is indexed by Science Citation Index (SciSearch), Scopus, International Pharmaceutical Abstract, Chemical Abstracts, Embase, Index Copernicus, EBSCO, African Index Medicus, JournalSeek, Journal Citation Reports/Science Edition, Directory of Open Access Journals (DOAJ), African Journal Online, Bioline International, Open-J-Gate and Pharmacy Abstracts

\section{INTRODUCTION}

During embryonic development cell fate decision is mainly regulated by polycomb group (PcG) proteins [1-3]. The two multi-protein complexes namely polycomb repressive complexes 1 and 2 (PRC1 and PRC2) are involved in repression of transcription. PRC2 comprises Ezh2 (enhancer of Zeste homolog 2), Suz12 (suppressor of Zeste 12), and EED (embryonic ectoderm development) [3]. The lysine methyl transfer and trimethylation of histone 3 at lysine 27 (H3K27me3) is performed by Ezh2 and Ezh2containing PRC2 respectively [4]. Several genome-wide integrative studies have revealed crucial roles of the polycomb pathway in cancer initiation and progression [5-7]. Ezh2 is highly expressed and its expression positively correlates with tumor malignancy and invasiveness in many cancers [8-10]. Based on 
this background, we investigated the histone methylation-independent role of EZH2 in GSC self-renewal and GBM propagation.

Berberine, an isoquinoline alkaloid of protoberberine class [11] inhibits cell growth in several types of human cancers [12-14]. It is reported to inhibit growth of cancer cells by inhibiting DNA topoisomerase I, inducing cellcycle arrest and apoptosis through Fas/FasL signalling pathways and activation of caspase- 3 [15]. There are reports that berberine can suppress the invasive properties of nasopharyngeal carcinoma cell lines through inhibiting the activities of Rho GTPases [16]. Berberine can suppress metastasis by enhancing the expression of a metastasis suppression gene, NM23-H1, or by targeting Rho kinasemediated ezrin phosphorylation in NPC 5-8 $\mathrm{F}$ cell line $[15,17]$. It also enhances the anti-cancer effects of estrogen receptor antagonists on human breast cancer cells (MCF-7) through down-regulating the expression of EGFR, HER2, $\mathrm{BCl}-2$, and $\mathrm{COX}-2$, as well as upregulating IFN- $\alpha$ and p21 [18]. With this wide spectrum of antitumor properties, berberine has potential application as a complementary medicine for treatment and possibly prevention of human cancers.

\section{EXPERIMENTAL}

\section{Cell culture and reagents}

Human esophageal cancer KYSE450 cells were purchased from the Health Science Research Resources Bank (Osaka, Japan). The cells were maintained in Dulbecco's Modified Eagle's Medium (DMEM; Invitrogen) with $10 \%$ FBS. Berberine, 5-aza-29-deoxycytidine (5-aza) and suberoylanilide hydroxamic acid (SAHA) were purchased from Sigma (St. Louis, MO, USA). Trichostatin A (TSA) was obtained from Cayman chemicals (Hamburg, Germany). Stock solutions of 5-aza, SAHA and TSA were prepared in dimethyl sulfoxide (DMSO) and that of DZNep in water.

\section{Migration and invasion assay}

Transwell motility chambers were used to analyse cell migration and invasion. For this, 8$\mathrm{mm}$ pore diameter transwell motility chambers (Corning) were coated with matrigel (BD Biosciences) on undesurface. Into the upper chamber, $2 \times 10^{6}$ cells were plated in serum-free culture medium and the lower chamber was filled with medium containing $10 \%$ FBS. The plates were incubated for $24 \mathrm{~h}$ at $37^{\circ} \mathrm{C}$. After incubation the upper surface of the compartment was cleaned. The inserts after methanol fixing were stained with crystal violet solution (0.5\%) followed by microscopic examination. The 5 areas were randomly selected and the cells were calculated. Experiments were performed in triplicates.

\section{Western blot analysis}

KYSE450 cells were treated with an ice cold solution of tris(hydroxymethyl) aminomethane hydrochloride (Carl Roth) containing $150 \mu \mathrm{M}$ $\mathrm{NaCl}, 1 \%$ Nondiet P-40 (Genaxxon Bioscience, Ulm, Germany), $10 \mu \mathrm{M}$ ethylenediaminetetraacetic acid (EDTA) (GerbuBiotechnik, Gaiberg, Germany), $200 \mu \mathrm{M}$ dithiothreitol (Carl Roth), $100 \mu \mathrm{M}$ phenylmethylsulphonyl fluoride (PMSF) and complete EDTA-free (1:50, Roche, Mannheim Germany) for 30 min. After lysis, the lysate was centrifuged for $20 \mathrm{~min}$ (12000 rpm) to remove the non-dissolved matter. Bio-Rad protein assay (Bio-Rad, Hercules, CA, USA) was used for estimation of protein concentration. Proteins were separated on SDS-PAGE and transferred to polyvinylidene difluoride (PVDF) membranes (Amersham Bioscience) blocked with milk. The membranes were then probed with antibodies. Chemiluminescence with the ECL system (Vigorous) was used for detection of protein bands as per the manufactures protocol.

\section{Cell cycle analysis}

Cells were incubated with $10 \mu \mathrm{M}$ bromodeoxyuridine (BrdU, BD Bioscience, Heidelberg, Germany) for $1 \mathrm{~h}$. After incubation the cells were harvested, fixed in ice-cold methanol and treated with a PBS-based buffer containing $0.1 \mathrm{M}$ hydrochloric acid (VWR) and $0.3 \%$ Triton $\mathrm{X}-100$ for $20 \mathrm{~min}$ at $4{ }^{\circ} \mathrm{C}$. The cells were then boiled in water to expose the DNA. Staining was performed for 30 min with AlexaFluor 647 mouse anti-BrdU antibody (clone 3D4, 1:50, BD Bioscience). Prior to flow cytometry using a BD FACS CANTO II cytometer (BD Biosciences), $20 \mathrm{mg} / \mathrm{mL}$ DAPI (Sigma-Aldrich) was added.

\section{Flow cytometer}

We used annexin-V/DAPI staining and flow cytometry for quantification of apoptotic cell death. For DZNep toxicity, cells were treated with DZNep for $120 \mathrm{~h}$, washed with PBS followed by treatment with Annexin-V-FITC and DAPI containing Annexin-binding buffer. Cells were then incubated for 10 min followed by flow cytometry examination using a BD FACS CANTO II cytometer. For AXL surface 
expression cells after incubation were harvested with accutase treatment (PAA), washed with PBS containing $3 \%$ FBS and $2 \mu \mathrm{M}$ EDTA. Again the cells were incubated with polyclonal goat antiAXL or polyclonal goat IgG on ice and then stained with secondary Alexa Fluor 488 goat anti-goat antibody (1:200, Invitrogen) for $30 \mathrm{~min}$.

\section{Quantitative real-time PCR}

Total RNA was isolated from KYSE450 cells using the Qiagen RNAeasy RNA isolation kit (Hilden, Germany). Using Applied Biosystems reverse-transcription-Kit (Foster City, CA, USA) one $\mathrm{mg}$ RNA was subjected to reverse transcription and $\mathrm{ABI} 7000$ thermal cycler with SYBR Green PCR Mastermix (Applied Biosystems, Carlsbad, USA) was used for QRTPCR. For relative quantification of gene expression threshold values were compared and glyceraldehyde-3-phosphate dehydrogenase (GAPDH) was used as housekeeping gene. All samples were analysed in triplicate and the results were normalized to GAPDH.

\section{Statistical analysis}

We used Student $t$ test with the SPSS13.0 statistical program for windows comparing EZH2 expression. The other data were expressed as the mean \pm SD. A value of $p$ less than 0.05 was considered to be statistically significant.

\section{RESULTS}

\section{Ezh2 expression in human esophageal cancer cell lines}

We observed a significant Ezh2 expression in esophageal carcinoma cells KYSE450, TE-1, $\mathrm{KY}-5, \mathrm{KY}-10, \mathrm{YES}-1$ and YES-2 compared to that in normal cells (Fig. 1A). The results revealed a strong correlation between intensity of staining and the extent of malignancy (Fig. 1B). Compared to invasion front, the expression of Ezh2 was stronger in perinecrotic areas (Fig. 1C). These results demonstrate that expression of Ezh2 is associated with malignant esophageal gliomas.

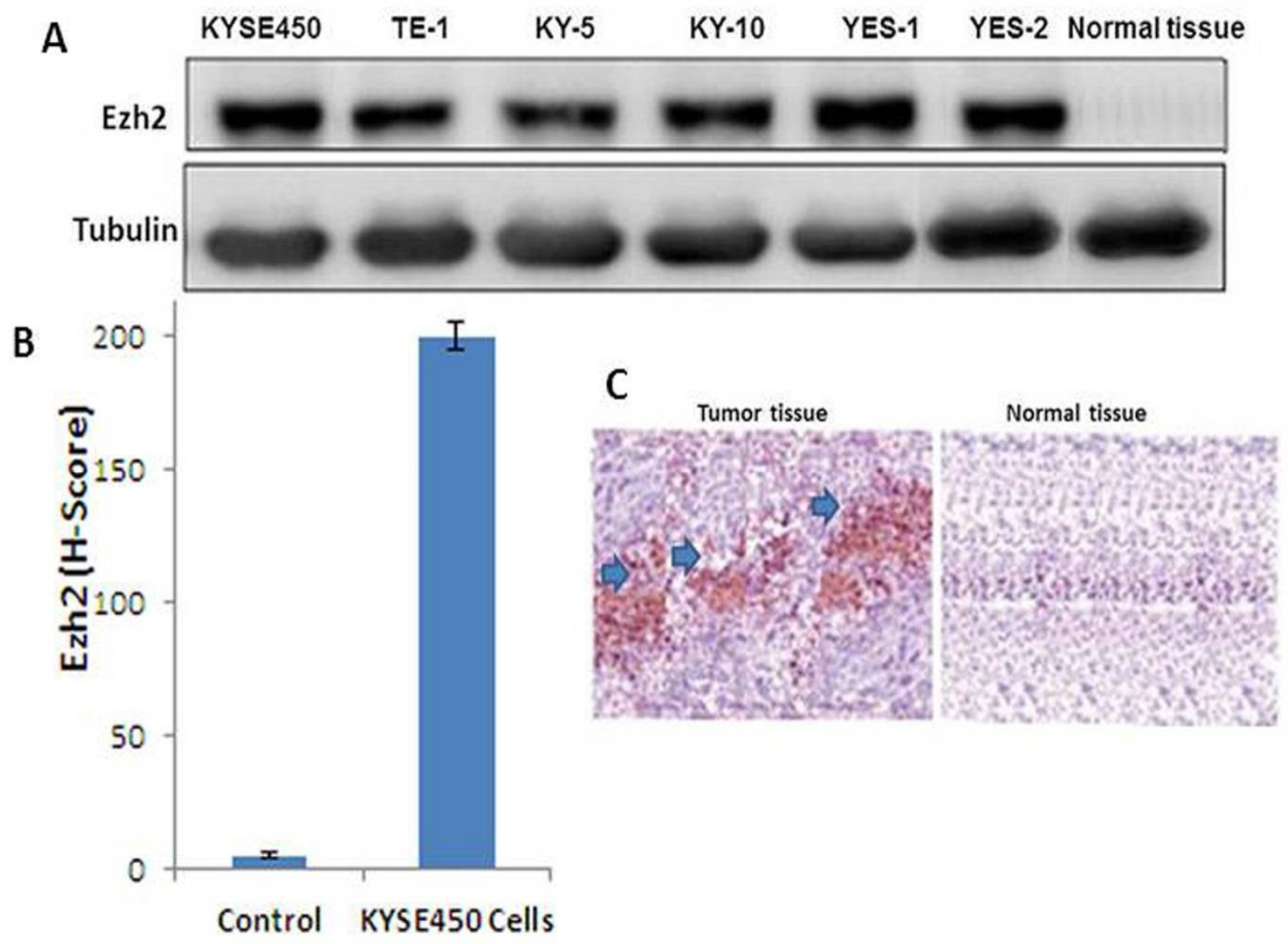

Fig 1: Ezh2 expression in human esophageal cancer cell lines. (A) Western blot showing Ezh2 expression in indicated cell lines using tubulin as loading control. (B) Ezh2 expression in KYSE450 cells. (C) Ezh2 expression in KYSE450 cells in necrotic regions 
Effect of berberine on Ezh2 expression, proliferation inhibition and invasion of carcinoma cell migration

Treatment of KYSE450 esophageal cancer cells with berberine led to inhibition of Ezh2 expression and the effect continued for 2 days (Fig 2A). Berberine treatment also inhibited cell proliferation by inducing a $\mathrm{G} 1$ phase cell cycle arrest (Fig 2B). Berberine-induced knockdown of Ezh2 resulted in anti-invasive properties of carcinoma cells in Boyden chamber assays. There was $92 \%$ reduction in invasive tendency of KYSE450 cells on treatment with berberine (Fig. 2C). For confirmation of Ezh2 inhibition by berberine treatment, the KYSE450 cells were treated with histone methylation inhibitor 3deazaneoplanocin A (DZNep). Although there was no toxic effect of DZNep treatment at $5 \mu \mathrm{M}$ concentration cell proliferation was inhibited to the same extent as after berberine treatment (Fig. 2D).

Treatment of KYSE450 carcinoma cells with berberine as well as with $5 \mu \mathrm{M}$ DZNep resulted in significant reduction of H3K27 trimethylation (Fig $2 \mathrm{E})$. However unlike berberine, treatment with DZNep did not result in inhibition of invasiveness in Boyden chamber assays (Fig 2F).

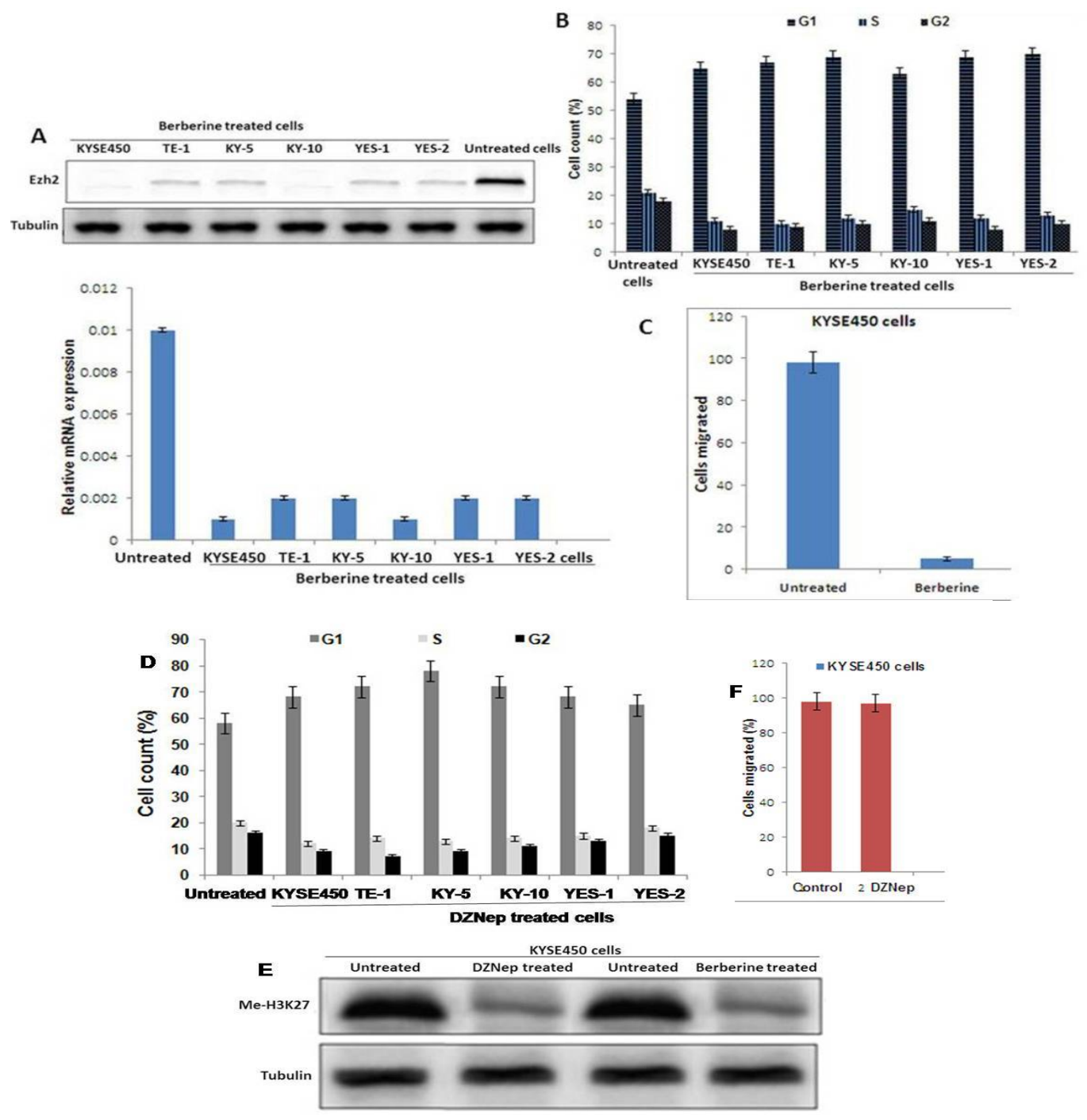

Fig 2: Effect of berberine on Ezh2 expression. (A) Western blot showing berberine treatment decreases Ezh2 expression after 24 hours using tubulin as loading control. (B) Cell cycle analysis of KYSE450 cells after 2 days of berberine treatment. (C) Migration of KYSE450 cells after berberine treatment through a matrigel-coated Boyden chamber. (D) Effect of DZNep $(5 \mu \mathrm{M})$ on H3K27me3 methylation. (E) Effect of DZNep $(5 \mu \mathrm{M})$ on H3K27me3 methylation or after berberine-induced Ezh2 inhibition. (F) Matrigel boyden chamber assay of KYSE450 cells 


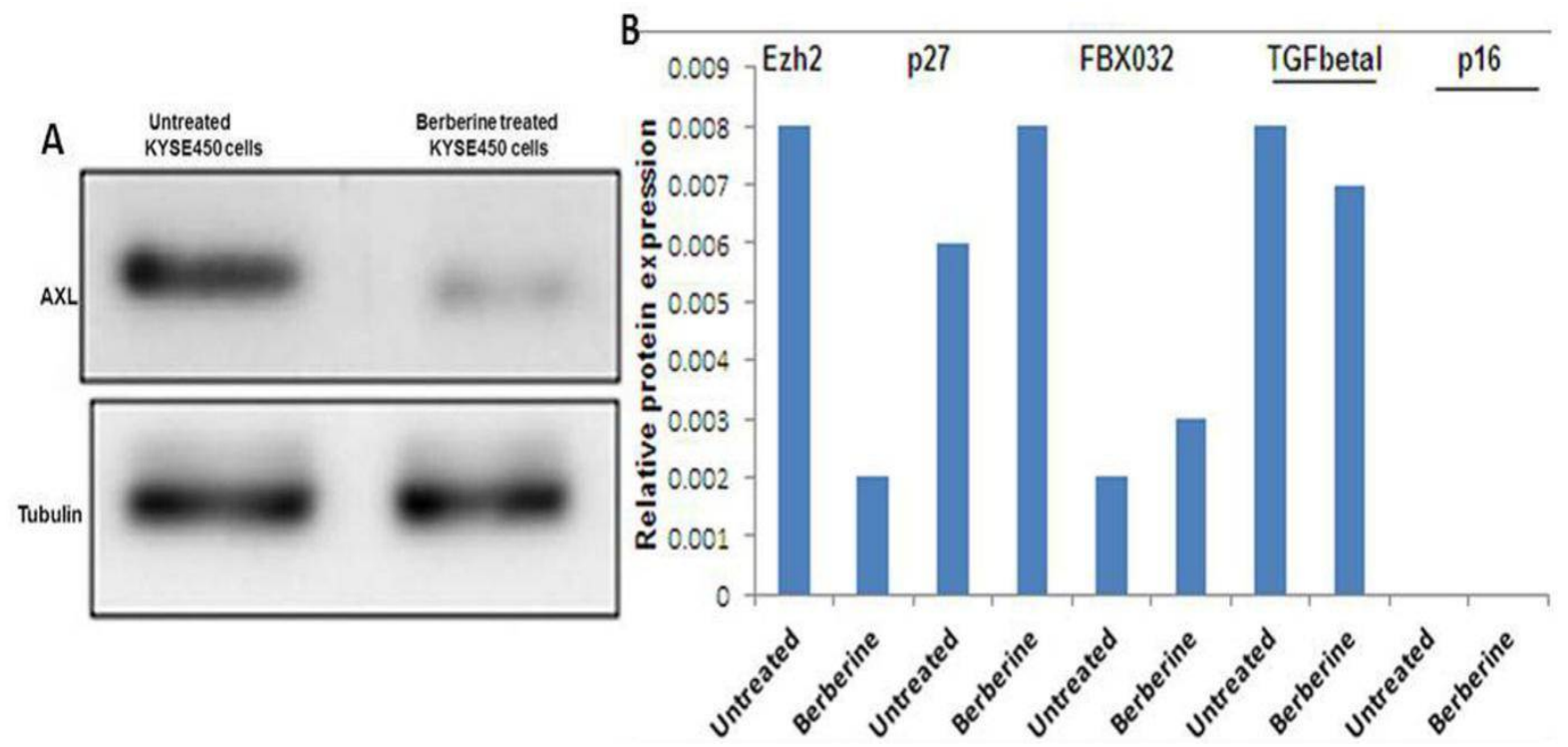

Fig 3: (A) AXL protein expression in the human KYSE450 carcinoma cells after treatment with berberine. (B) Analysis of protein expression in KYSE450 carcinoma cells after treatment with berberine

Transcriptional profiling of Ezh2-knockdown in human malignant cancer cells

We observed significant inhibition of the gene receptor tyrosine kinase AXL in KYSE450 carcinoma cells after berberine treatment (Fig $3 A)$. The results from $q R T-P C R$ and FACS analyses showed significant inhibition of $A X L$ mRNA and protein expression in KYSE450 carcinoma cells after treatment with berberine (Fig 3B).

\section{DISCUSSION}

The gene receptor tyrosine kinase AXL has been shown to be involved in tumor invasiveness and metastases in multiple tumors [20-24]. There are reports that berberine can suppress the invasive properties [25] and suppress metastasis by enhancing the expression of a metastasis suppression gene, NM23-H1, or by targeting Rho kinase-mediated ezrin phosphorylation in NPC 5$8 \mathrm{~F}$ cell line $[22,26]$. We observed a significant inhibition of AXL mRNA and protein expression in KYSE450 carcinoma cells after treatment with berberine. Ezh2 is believed to regulate cell motility through AXL transactivation in cancer cells as well as in stem cells during development. In KYSE450 carcinoma cells which are known to possess migration tendency we observed a strong Ezh2 expression in perinecrotic areas. Berberine treatment led to suppression of Ezh2 expression and inhibition of cell proliferation by inducing a $\mathrm{G} 1$ phases cell cycle arrest. Berberine induced suppression of Ezh2 also resulted antiinvasive properties of KYSE450 carcinoma cells. Berberine treatment led to inhibition of the stem cell marker nestin which correlates with earlier reports [13] depicting the key role of Ezh2 for maintaining a stem cell phenotype in malignant cancers.

Recent studies indicate that DZNep globally suppresses histone methylation [27]. Inhibition of histone trimethylation by DZNep not only depletes Ezh2 by inducing its proteasomal degradation but also other proteins of the PRC2 complex $[26,28,29]$. The results from our study demonstrate that Ezh2 activates transcription of AXL mRNA in a methylation-independent manner. Treatment of KYSE450 carcinoma cells with DZNep did not affect AXL expression. It is possible that other components of the PRC2 such as SUZ12 or EED silence AXL mRNA expression while Ezh2 positively regulates AXL. While we initially postulated that HDAC are directly involved in mediating modulation of $A X L$ transcription by $E Z H 2$ in gliomas, our data suggest that inhibition of HDAC suppress AXL transcription by transcriptional control of Ezh2, indicating that Ezh2 is under transcriptional control of HDAC also in KYSE450 carcinoma cells. Although the exact molecular mechanisms driving $A X L$ gene expression through EZH2 remain elusive, the identification of $A X L$ as a novel target of Ezh2 adds further evidence to the molecular network influenced by Ezh2 to sustain the malignant phenotype of tumors.

\section{CONCLUSION}

The findings of this study demonstrate that berberine-induced inhibition of Ezh2 expression leads to inhibition of cell proliferation by $\mathrm{G} 1$ 
phase cell cycle arrest and induces anti-invasive properties of KYSE450 cells in Boyden chamber assays. Thus, berberine may be an effective therapeutic agent in the treatment of esophageal carcinoma.

\section{REFERENCES}

1. Margueron $R$, Reinberg $D$. The Polycomb complex PRC2 and its mark in life. Nature 2011; 469: 343-349.

2. Richly H, Aloia L, Di-Croce L. Roles of the Polycomb group proteins in stem cells and cancer. Cell Death Dis 2011; 2: 204.

3. Sparmann A, Van LM. Polycomb silencers control cell fate, development and cancer. Nat. Rev. Cancer 2006; 6: 846-856.

4. Cao $R$, Wang L, Wang $H$, Xia L, Erdjument-Bromage $H$, Tempst $P$, Jones RS, Zhang $Y$. Role of histone $H 3$ lysine 27 methylation in Polycomb-group silencing. Science 2002; 298: 1039-1043.

5. Schlesinger $Y$, Straussman $R$, Keshet I, Farkash $S$, Hecht M, Zimmerman J, Eden E, Yakhini Z, BenShushan., Reubinoff BE, et al. Polycomb-mediated methylation on Lys27 of histone H3 premarks genes for de novo methylation in cancer. Nat. Genet. 2007; 39: 232-236.

6. Vire, E, Brenner C, Deplus $R$, Blanchon L, Fraga $M$, Didelot C, Morey L, Van Eynde A, Bernard $D$, Vanderwinden JM, et al. The Polycomb group protein EZH2 directly controls DNA methylation. Nature 2006; 439: 871-874.

7. Widschwendter M, Fiegl H, Egle D, Mueller-Holzner E, Spizzo G, Marth C, Weisenberger DJ, Campan M, Young J, Jacobs I, Laird PW. Epigenetic stem cell signature in cancer. Nat. Genet. 2007; 39: 157-158.

8. Crea F, Hurt EM, Farrar WL. Clinical significance of Polycomb gene expression in brain tumors. Mol Cancer 2010; 9: 265-267.

9. Kleer $C G, C a o$, , Varambally $S$, Shen R, Ota I, Tomlins $S A$, Ghosh $D$, Sewalt RG, Otte AP, Hayes $D F$, et al. $E Z H 2$ is a marker of aggressive breast cancer and promotes neoplastic transformation of breast epithelial cells. Proc Nat Acad Sci USA 2003; 100: 11606-11611.

10. Varambally S, Dhanasekaran SM, Zhou M, Barrette TR, Kumar-Sinha C, Sanda MG, Ghosh, D, Pienta KJ, Sewalt RG, Otte $A P$, et al. The polycomb group protein EZH2 is involved in progression of prostate cancer. Nature 2002; 419: 624-629.

11. Sun $Y$, Xun $K$, Wang $Y$, Chen $X$. A systematic review of the anticancer properties of berberine, a natural product from Chinese herbs. Anti-Cancer Drugs 2009; 20: 757-769.

12. Katiyar SK, Meeran SM, Katiyar N, Akhtar S. p53 Cooperates berberine induced growth inhibition and apoptosis of non-small cell human lung cancer cells in vitro and tumor xenograft growth in vivo. Mol Carcinogen 2009; 48, 24-37.
13. Kim JB, Yu JH, Ko E, Lee KW, Song AK, Park SY, Shin I, Han W, Noh DY. The alkaloid Berberine inhibits the growth of Anoikis-resistant MCF-7 and MDA-MB-231 breast cancer cell lines by inducing cell cycle arrest. Phytomed 2010; 17: 436-440.

14. Wang XN, Han $X, X u L N$, Yin LH, Xu YW, Qi Y, Peng JY. Enhancement of apoptosis of human hepatocellular carcinoma SMMC-7721 cells through synergy of berberine and evodiamine. Phytomed 2008; 15: 1062-1068.

15. Tang $F$, Wang $D$, Duan $C$, Huang $D$, Wu $Y$, Chen $Y$, Wang W, Xie C, Meng J, Wang L. Berberine inhibits metastasis of nasopharyngeal carcinoma 5-8 F cells by targeting Rho kinase-mediated Ezrin phosphorylation at threonine 567. J Biol Chem 2009; 284 : 27456-27466.

16. Tang J, Feng $Y$, Tsao S, Wang N, Curtain R, Wang $Y$. Berberine and Coptidis rhizoma as novel antineoplastic agents: a review of traditional use and biomedical investigations. J Ethnopharmacol 2009; 126: 5-17.

17. Liu SJ, Sun YM, Tian DF, He YC, Zeng L, He Y, Ling CQ, Sun SH. Downregulated NM23-H1 expression is associated with intracranial invasion of nasopharyngeal carcinoma. Brit J Cancer 2008; 98: 363-369.

18. Liu J, He C, Zhou K, Wang J, Kang JX. Coptis extracts enhance the anticancer effect of estrogen receptor antagonists on human breast cancer cells. Biochem Biophys Res Commun 2009; 378: 174-178.

19. Lee J, Son MJ, Woolard K, Donin NM, Li A. Epigeneticmediated dysfunction of the bone morphogenetic protein pathway inhibits differentiation of glioblastoma-initiating cells. Cancer Cell 2008; 13: 69-80.

20. Avilla E, Guarino V, Visciano C, Liotti $F$, Svelto $M$. Activation of TYRO3/AXL tyrosine kinase receptors in thyroid cancer. Cancer Res 2011; 71: 1792-1804.

21. Li Y, Ye X, Tan C, Hongo JA, Zha J. Axl as a potential therapeutic target in cancer: role of $A x I$ in tumor growth, metastasis and angiogenesis. Oncogene 2009; 28: 3442-3455.

22. Liu $R$, Gong M, Li X, Zhou Y, Gao W. Induction, regulation, and biologic function of $A x I$ receptor tyrosine kinase in Kaposi sarcoma. Blood 2010; 116: 297-305.

23. Rankin EB, Fuh KC. Taylor TE, Krieg AJ, Musser M. AXL is an essential factor and therapeutic target for metastatic ovarian cancer. Cancer Res 2010; 70: 7570-7579.

24. Song $X$, Wang $H$, Logsdon $C D$, Rashid A, Fleming JB. Overexpression of receptor tyrosine kinase $A x I$ promotes tumor cell invasion and survival in pancreatic ductal adenocarcinoma. Cancer 2011; 117: 734-743.

25. Tsang CM, Lau EP, Di K, Cheung PY, Hau PM, Ching YP, Wong YC, Cheung AL, Wan TS, Tong Y, et al. Berberine inhibits Rho GTPases and cell migration at

Trop J Pharm Res, September 2015; 14(9): 1594 
low doses but induces G2 arrest and apoptosis at high doses in human cancer cells. Int $\mathrm{J}$ Mol Med 2009; 24: 131-138.

26. Tan J, Yang $X$, Zhuang $L$, Jiang $X$, Chen $W$. Pharmacologic disruption of Polycomb-repressive complex 2-mediated gene repression selectively induces apoptosis in cancer cells. Genes Dev 2007; 21: 1050-1063.

27. Miranda TB, Cortez CC, Yoo CB, Liang G, Abe MDZNep is a global histone methylation inhibitor that reactivates developmental genes not silenced by DNA methylation. Mol Cancer Ther 2009; 8: 15791588.
28. Fiskus W, Buckley $K$, Rao R, Mandawat A, Yang $Y$. Panobinostat treatment depletes EZH2 and DNMT1 levels and enhances decitabine mediated derepression of JunB and loss of survival of human acute leukemia cells. Cancer Biol Ther 2009; 8: 939950.

29. Fiskus $W$, Pranpat $M$, Balasis $M$, Herger $B$, Rao $R$. Histone deacetylase inhibitors deplete enhancer of zeste 2 and associated polycomb repressive complex 2 proteins in human acute leukemia cells. Mol Cancer Ther 2006; 5: 3096-3104. 